\title{
Using Video Messages to Promote Residential Adoption of Fertilizer Best Practices'
}

\author{
Amanda D. Ali, Laura A. Sanagorski Warner, Peyton Beattie, Alexa J. Lamm, and Joy N. \\ Rumble ${ }^{2}$
}

\section{Introduction}

Residents may be inclined to over-irrigate and over-fertilize their lawns to uphold landscape appearances influenced by homeowner associations and neighborhood aesthetics (Nielson \& Smith, 2005). These activities affect both water quantity and water quality; however, water quality is associated more with fertilizer practices (Nielson \& Smith, 2005; Toor et al., 2017). The Florida Department of Agriculture and Consumer Services noted "excess nitrogen and phosphorus are the most common causes of water quality impairments in Florida" (FDACS, 2014). Proper management of nutrient sources and pollutant discharge is crucial for safeguarding clean water resources (FDACS, 2014). Support for water programs and engagement in fertilizer best management practices (BMPs) can also have positive impacts on water quality. Understanding how residents perceive various attributes of engagement in fertilizer BMPs can help Extension program planners design effective water conservation programs. The Diffusion of Innovation (DOI) Theory (Rogers, 2003) outlines five attributes of an innovation which were used in the context of fertilizer BMPs for this study. While these attributes can inform water programming, it is also important to consider how this information can be communicated. Therefore, the purpose of the study described in this document was to determine if video messages about fertilizer BMPs influenced residents' perceptions of fertilizer use related to the DOI attributes.

\section{Encouraging Residential Adoption of Fertilizer Best Practices}

The DOI theory explains how an idea or product considered new by a population is accepted and adopted over time (Rogers, 2003). The theory states that five attributes influence the diffusion of an innovation: relative advantage, compatibility, complexity, observability, and trialability. In relation to fertilizer best management practices and residents, these attributes translate to:

- the degree to which fertilizer BMPs are perceived as better than current fertilizer practices (relative advantage)

- the degree to which fertilizer BMPs are perceived as consistent with the existing needs of residents (compatibility)

- the degree to which fertilizer BMPs are perceived as difficult to understand and use (complexity)

- whether the results of using fertilizer BMPs are visible to others (observability)

- the degree to which fertilizer BMPs can be experimented with before committing to adoption (trialability)

If all five attributes are favorable-fertilizer BMPs are perceived as better than current practices, consistent with existing values and needs of residents, and easy to understand and use; results of using fertilizer BMPs are visible to others; and residents can engage in fertilizer BMPs before

1. This document is AEC646, one of a series of the Agricultural Education and Communication Department, UF/IFAS Extension. Original publication date July 2018. Visit the EDIS website at http://edis.ifas.ufl.edu.

2. Amanda D. Ali, graduate student; Laura A. Sanagorski Warner, assistant professor; Peyton Beattie, graduate student; Alexa J. Lamm, former associate professor; and Joy N. Rumble, assistant professor; Department of Agricultural Education and Communication, UF/IFAS Extension, Gainesville, FL 32611.

The Institute of Food and Agricultural Sciences (IFAS) is an Equal Opportunity Institution authorized to provide research, educational information and other services

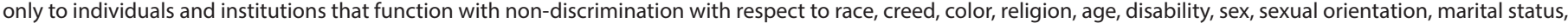

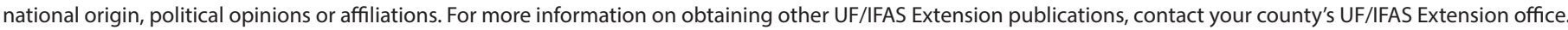
U.S. Department of Agriculture, UF/IFAS Extension Service, University of Florida, IFAS, Florida A \& M University Cooperative Extension Program, and Boards of County Commissioners Cooperating. Nick T. Place, dean for UF/IFAS Extension. 
committing-adoption is likely. Understanding residents' perceptions of these attributes can help inform effective water quality programs. Extension professionals can consider these attributes when designing and promoting adoption of fertilizer best practices.

\section{Exploring Residents' Perceptions of Fertilizer Use Through Video}

A team of researchers from the University of Florida Center for Landscape Conservation and Ecology and Center for Public Issues Education surveyed 2,000 Florida residents who had a home lawn or home landscape and who engaged in fertilizer practices. Video messages were developed around social and personal engagement in fertilizer BMPs. There were two treatment groups: those who received a social-themed video message, those who received a personal themed video message, and a control group who received no video message. Both videos highlighted the use of fertilizer BMPs (such as reading fertilizer labels) and discussed the importance of fertilizer BMPs in protecting water quality. We used Chi-square tests to determine associations between the treatment and control groups for relative advantage, observability, and trialability, and also used ANOVA analyses to test differences in video treatment and control groups for compatibility and complexity.

Respondents were asked to indicate their level of agreement with statements pertaining to the DOI characteristics. Responses were measured on a five-point Likert scale ranging from strongly disagree to strongly agree, and not at all likely to very likely. The Chi-square tests indicated a statistically significant difference between the social and personal video groups for the following questions or statements: "Good fertilizer practices are better than the fertilizer practices I have used in the past" $\left(X^{2}(8)=45.48, p<.01, \mathrm{n}^{2}=.15\right)$ and "Have you had the opportunity to observe others using or demonstrating good fertilizer practices you are not currently using?" $\left(X^{2}(2)=15.75, p<.01, \mathrm{n}^{2}=.11\right)$. When asked, "How likely are you to adopt good fertilizer practices you observed someone else using?" results showed no statistically significant difference between groups. However, there was a statistically significant difference when asked if good fertilizer practices can be tested before committing to changing management routine $\left(X^{2}(8)=27.60, p<.01, \mathrm{n}^{2}\right.$ $=.13)$. ANOVA results also showed statistically significant differences between the video groups and the control group in residents' perceptions of compatibility $(p<.01)$ and complexity $(p<.01)$. Statistical differences were found between the control group and the personal video group ( $p$
$<.01)$ and the social video group $(p<.01)$ for compatibility and complexity.

\section{Summary of Findings}

Videos positively influenced residents' perceptions of fertilizer BMPs, but the type of video (social or personal themes) did not matter in this study. This implies videos can be used over time to help residents understand the relative advantage, compatibility, complexity, observability, and trialability attributes of adopting fertilizer BMPs. More research is needed to examine the most effective content and approach.

\section{How to Use This Information}

The changes in perceptions of DOI characteristics brought about by the videos imply extension professionals can use videos to influence perceptions towards, and possibly adoption of, fertilizer BMPs. Extension professionals designing water quality and fertilizer best management practice programs should consider the five DOI attributes and how the use of videos can stimulate engagement in fertilizer BMPs. Some recommendations to consider when communicating the DOI attributes through videos are:

- Making known the benefits of engaging in fertilizer best management practices (relative advantage attribute). Our videos highlighted that the result of using fertilizer BMPs was the continuance of Florida's rivers, lakes, and springs as a place for people to enjoy. This may have increased perceptions of relative advantage. Extension professionals should consider integrating the value of enjoying water resources when they design videos to promote good fertilizer practices. To communicate the relative advantage at the household scale, Extension professionals can partner with HOAs and realtors to promote the environmental and wellbeing benefits of fertilizer BMPs. Partnerships among these organizations can provide information packages on good lawn care practices to residents and potential buyers looking at model homes. Links to video messages promoting fertilizer BMPs can be included in these packages. Extension professionals can take this opportunity to showcase fertilizer BMPs used in landscapes surrounding model homes. This opportunity shows potential buyers that aesthetic landscapes are achievable using fertilizer BMPs, and can also stimulate a positive atmosphere that promotes wellbeing. Such information can help increase the likelihood of engaging in fertilizer BMPs. Video messages about fertilizer BMPs with insight from existing residents already using these practices can be a part of events. Residents can interact with others 
currently using BMPs through meet-and-greet sessions where questions and concerns can be addressed.

- Ensuring that fertilizer BMPs are similar to residents' existing values and beliefs (compatibility attribute).

Residents may consider the cost of engaging in fertilizer BMPs. If they believe the cost is beyond their current budget and they are not willing to pay more than they would for their current practices, adoption of fertilizer BMPs may be low. One way Extension professionals can increase perceptions of compatibility is to communicate how the use of good fertilizer practices can save money, directly through reduced landscape inputs and indirectly through healthier turfgrass and plants. With the use of video messages explaining cost and savings, residents could become aware of potential savings if they follow these practices.

- Demonstrating fertilizer best practices are easy to use (complexity attribute). It is important to highlight that engaging in fertilizer BMPs is not time-consuming or difficult. Residents may not switch to BMPs if these practices take longer to complete than current fertilizer practices or if they are confusing. Videos demonstrating simple steps of how to engage in fertilizer BMPs can show it is no more time-consuming than current practices, and that these practices are easy to understand and use.

- Showing landscapes that use fertilizer best practices so results can be observed by others (observability attribute). Extension professionals can design videos that highlight landscapes managed with fertilizer BMPs. Extension professionals might also ask residents already using fertilizer BMPs to create home videos to showcase their landscapes and talk about steps taken to achieve aesthetic landscapes. Their experience using fertilizer BMPs can be viewed as credible by others in the community and can stimulate adoption. Through a "landscape expo" event hosted by Extension professionals, residents can show their videos and their actual landscapes, which can encourage others to engage in using fertilizer BMPs.

- Providing opportunities for a trial period so residents can experiment with fertilizer best practices before deciding to fully commit (trialability attribute). Extension professionals could develop interactive videos or host in-person "DIY day" events where residents are shown how to use fertilizer BMPs and given the opportunity to try them, either virtually or in-person. Through these events, residents could have the opportunity to engage in these practices before deciding to fully adopt. If the trial period runs for a few weeks, residents can video-record their experiences so changes before and after are noted. At the end of the trial period, through another Extension day-event, residents can exchange ideas and experiences about their involvement with fertilizer BMPs and showcase their videos for others to see the transformation in their landscapes.

\section{Acknowledgements}

The authors thank the University of Florida Center for Landscape Conservation and Ecology for supporting the work shared in this publication.

\section{References}

Florida Department of Agriculture and Consumer Services (FDACS). (2014). Water quality / quantity best management practices for Florida Nurseries. Retrieved from http://www. freshfromflorida.com/content/download/37570/848371/ nurseryBMPlores.pdf

Nielson, L., \& Smith, C. L. (2005). Influences on residential yard care and water quality: Tualatin watershed, Oregon. Journal of the American Water Resources Association, 41(1), 93-106. doi:10.1111/j.1752-1688.2005.tb03720.x

Rogers, E. M. (2003). Diffusion of innovations (5th ed.). New York: Free Press.

Toor, G. S., Occhipinti, M. L., Yang, Y-Y., Majcherek, T., Haver, D., \& Oki, L. (2017). Managing urban runoff in residential neighborhoods: Nitrogen and phosphorus in lawn irrigation driven runoff. PLOS One, 12(6), 1-17. doi: 10.1371/journal.pone.0179151 